\title{
Ensino médio no Ceará: igualdade versus qualidade na implementação do direito à educação
}

Sofia Lerche Vieira* Eloísa Maia Vidal**

\begin{abstract}
*(Universidade Estadual do Ceará - Uece - Fortaleza, CE) ** (Universidade Estadual do Ceará Uece -, Fortaleza, CE)
\end{abstract} Resumo: 0 artigo analisa o processo de implementação das políticas educacionais e a assimilação e incorporação destas pelas escolas visando promover a qualidade e a equidade educacional na formação dos estudantes. Sintetiza resultados de pesquisa desenvolvida em uma amostra de seis escolas de ensino médio, localizadas em três municípios do Ceará, mediante a realização de estudos de natureza quanti-qualitativa, incluindo análise de indicadores, revisão de literatura, análise documental e pesquisa de campo. A investigação revelou forte presença da avaliação de larga escala e a diversificação da oferta escolar. Constatou que $88 \%$ dos alunos estão em escolas de ensino regular de um turno e $12 \%$ em escolas de ensino médio profissional de tempo integral. As condições de ensino-aprendizagem entre esses dois tipos de oferta são diferenciadas e agravadas nas chamadas "extensões rurais" ou anexos, onde estudam $11 \%$ dos alunos. Tal situação tem contribuído para uma diversificação da oferta marcada por elementos de iniquidade.

Palavras-chave: Ceará. Ensino médio. Desigualdades socioespaciais. Diversificação da oferta. 


\section{INTRODUÇÃO}

O ensino médio tem sido objeto de crescente interesse por parte de formuladores e estudiosos da política educacional, tanto no que se refere à expansão e às condições de oferta, como no que diz respeito aos indicadores de rendimento e à atratividade da escola para a juventude. Visando compreender como diferentes unidades da federação têm respondido a esses desafios, o Centro de Estudos e Pesquisas em Educação e Ação Comunitária (Cenpec) e a Fundação Tide Setubal desenvolveram em 2015 o projeto de pesquisa "Políticas para o ensino médio: o caso de quatro estados".

Este artigo sintetiza resultados da pesquisa no Ceará, processo que envolveu estudos de natureza quanti-qualitativa, incluindo análise de indicadores, revisão da literatura, análise documental, entrevistas com dirigentes educacionais e pesquisa de campo. 0 estudo abrangeu três municípios de porte diferenciados, incluindo seis escolas estaduais, sendo duas de ensino médio regular e quatro de ensino médio integrado à educação profissional.

As seis escolas selecionadas para a pesquisa apresentam configurações peculiares em relação aos tipos de oferta. As quatro escolas de ensino médio integrado à educação profissional apresentam matrículas entre 332 e 449 alunos, funcionam em tempo integral e, embora estejam localizadas em territórios potencialmente vulneráveis, recebem os alunos das comunidades do entorno que possuem melhores desempenhos nas séries finais do ensino fundamental, admitidos mediante mecanismos de seleção cujos critérios incluem resultados de aprendizagem. As duas escolas de ensino médio regular apresentam matrículas superiores a 1.300 alunos, funcionam nos três turnos com oferta de ensino médio e, além dessa etapa de educação, oferecem outras etapas ou modalidades de ensino, como séries finais do ensino fundamental e educação de jovens e adultos. Essas escolas, também situadas em regiões de alta vulnerabilidade social, não estabelecem critérios para admissão de alunos, o que as leva a uma maior complexidade da gestão não apenas pela quantidade de alunos, mas pela diversidade de níveis e etapas de escolaridade oferecidos e turnos de funcionamento.

A variável distorção idade-série foi observada nas seis escolas no ano de 2014 e constatou-se que a taxa média das duas escolas que ofertam ensino médio regular é 5,6 vezes maior do que nas escolas de educação profissional. As duas escolas que oferecem ensino médio regular funcionam nos três turnos, sendo o turno noturno o que abriga educação de jovens e adultos e ensino médio para alunos trabalhadores e apresenta maior distorção idade-série. 
Tais informações confirmam o estudo realizado por Castro e Tavares Junior (2016, p. 252), que afirma que os "casos de sucesso escolar estão alocados, principalmente, nos turno da manhã $(51,6 \%)$, noite $(24,3 \%)$ e tarde $(24,1 \%)$, e os casos de não sucesso escolar estão inseridos, em maiores proporções, no turno da noite $(45,35 \%)$ ". Os dados de distorção apontam o histórico de irregularidade da vida escolar do aluno, seja por reprovação ou abandono de um ou mais anos escolares.

O depoimento do diretor de uma escola mostra essa compreensão ao afirmar que

A maioria das escolas quando vê os índices sendo arrastados para baixo, associa logo a quem? Ao turno da noite, infelizmente. Aí você acaba tendo uma educação desigual, com resultados também desiguais no mesmo ambiente. Isso é uma situação muito complicada (Ceará, diretor de escola de município de grande porte).

Os níveis socioeconômicos das escolas cearenses pesquisadas mostram o que Castro e Tavares Junior (2016) explicitam no seu estudo ao afirmar que

É possivel observar que muitos jovens, mesmo pertencendo a classes sociais menos favorecidas, almejam os niveis educacionais mais elevados e a esperada mobilidade social, mesmo sem os meios ideais para persegui-los, avaliando os prováveis custos, riscos e benefícios, descrevendo trajetórias escolares heterogêneas (CASTRO; TAVARES JUNIOR, 2016,

Esse desejo de mobilidade social é claramente percebido nos alunos das escolas de ensino médio integrado à educação profissional, que embora se situem em níveis socioeconômicos similares ao dos alunos das escolas de ensino médio regular, são portadores de uma visão de futuro mais ambiciosa e estão dispostos a fazer "sacrifícios" imediatos em nome deste devir.

A questão norteadora da pesquisa diz respeito a quais políticas públicas são implementadas nos âmbitos nacional e estadual e de que forma as escolas assimilam, incorporam e implementam essas políticas no sentido de promover a qualidade e a equidade educacional dos jovens que as frequentam. Para lançar luzes sobre essa questão nas escolas cearenses, foi necessário recorrer a uma análise da trajetória recente do ensino público no Ceará. 


\section{BREVE HISTÓRICO dA ORGANIZAÇÃO dO ENSINO PÚBLICO NO CEARÁ}

0 modelo de federalismo adotado pelo Estado brasileiro atribui responsabilidades diferenciadas à União, aos estados, ao Distrito Federal e aos municípios na formulação e implementação de políticas sociais.

No caso do Ceará, é oportuno registrar o avançado processo de municipalização do ensino fundamental. Dados obtidos junto aos censos escolares da educação básica mostram que, em 1992, a matrícula do ensino fundamental nas redes municipais já era maior que a da rede estadual e que o processo de municipalização dessa etapa evoluiu no sentido de redução da participação da rede estadual, chegando em 2014 a 4,9\%, a menor proporção nas subunidades nacionais.

O processo de municipalização adotado pelo estado do Ceará, especialmente depois da criação do Fundo de Desenvolvimento do Ensino Fundamental e de Valorização do Magistério (Fundef), comprometeu de forma aguda o financiamento da oferta de ensino médio, etapa da educação básica de responsabilidade do estado. Um exemplo de tal situação foi o impacto financeiro junto à folha de pagamento dos professores de ensino médio. Como os docentes atuavam de forma compartilhada no ensino médio e em escolas que ofertavam as duas etapas, foi possivel em um primeiro momento que seus salários fossem bancados com recursos do Fundef. A municipalização dos anos finais do ensino fundamental, todavia, eliminou essa possibilidade, cabendo ao estado assumir integralmente, com recursos do Tesouro Estadual, as despesas com pessoal no ensino médio, em momento de acelerado crescimento de matrículas.

Os problemas de financiamento do ensino médio só são resolvidos com a aprovação da Emenda Constitucional no 53/2006, que cria o Fundo de Manutenção e Desenvolvimento da Educação Básica e de Valorização dos Profissionais da Educação (Fundeb), instituído em 2007. Assim, ao assumir o governo, Cid Gomes (2007-2014) depara com um cenário financeiro bastante favorável para o estabelecimento de uma política de ensino médio mais robusta e com a possibilidade de implementação de novas iniciativas.

O período 1998-2006 é fortemente marcado pelo crescimento da demanda de ensino médio, chegando a rede estadual a crescer uma média de 11,3\% por ano, como mostra a Tabela 1. Esse crescimento é decorrente de algumas medidas adotadas no ensino fundamental como, por exemplo, ações para correção de fluxo escolar e diminuição das taxas de reprovação e abandono, 
no fim dos anos 1990, quando da implantação do Fundef. Os dados revelam predominância da matrícula pública na oferta de tal etapa da educação básica, registrando também, no intervalo, a redução na rede particular de ensino e o crescimento do percentual das matrículas na escola pública. Nesse período ainda se observa oferta de ensino médio nas redes municipais, fato que vai gradativamente desaparecendo.

Tabela 1 - Matrículas no ensino médio por dependência administrativa no Ceará, $1998-2006$

\begin{tabular}{|c|c|c|c|c|c|c|c|c|c|}
\hline Dep. Adm. & 1998 & 1999 & 2000 & 2001 & 2002 & 2003 & 2004 & 2005 & 2006 \\
\hline Estadual & 146.444 & 190.046 & 201.690 & 232.831 & 318.553 & 318.553 & 339.727 & 368.751 & 373.182 \\
\hline Municipal & 18.745 & 9.657 & 4.127 & 2.072 & 1.525 & 1.737 & 1.859 & 1.477 & 1.477 \\
\hline Particular & 53.386 & 58.239 & 55.177 & 56.185 & 56.544 & 56.051 & 54.276 & 50.216 & 50.216 \\
\hline Total & 218.575 & 257.942 & 260.994 & 291.088 & 334.892 & 376.341 & 395.862 & 420.444 & 424.875 \\
\hline $\begin{array}{c}\% \text { crescimento } \\
\text { em relação ao ano } \\
\text { anterior }\end{array}$ & $29,8 \%$ & $6,1 \%$ & $15,4 \%$ & $18,9 \%$ & $15,1 \%$ & $6,6 \%$ & $8,5 \%$ & $1,2 \%$ \\
\hline $\begin{array}{c}\% \text { de matrículas na } \\
\text { rede estadual }\end{array}$ & $67,0 \%$ & $73,7 \%$ & $77,3 \%$ & $80,0 \%$ & $82,7 \%$ & $84,6 \%$ & $85,8 \%$ & $87,7 \%$ & $87,8 \%$ \\
\hline
\end{tabular}

Fonte: Instituto Nacional de Estudos e Pesquisas Educacionais Anísio Teixeira (Inep)/Sinopses Estatísticas da Educação Básica.

A partir de 2006, a oferta de ensino médio na rede estadual se estabiliza, como mostra o Gráfico 1, e simultaneamente se registra crescimento contínuo de recursos provenientes do Fundeb (no período 2007-2015 os recursos do Fundeb para o estado cresceram $285,2 \%$ ), criando condições objetivas de planejar e diversificar a oferta desta etapa de ensino. 
Gráfico 1 - Matrículas no ensino médio por dependência administrativa, Ceará 2007-2014

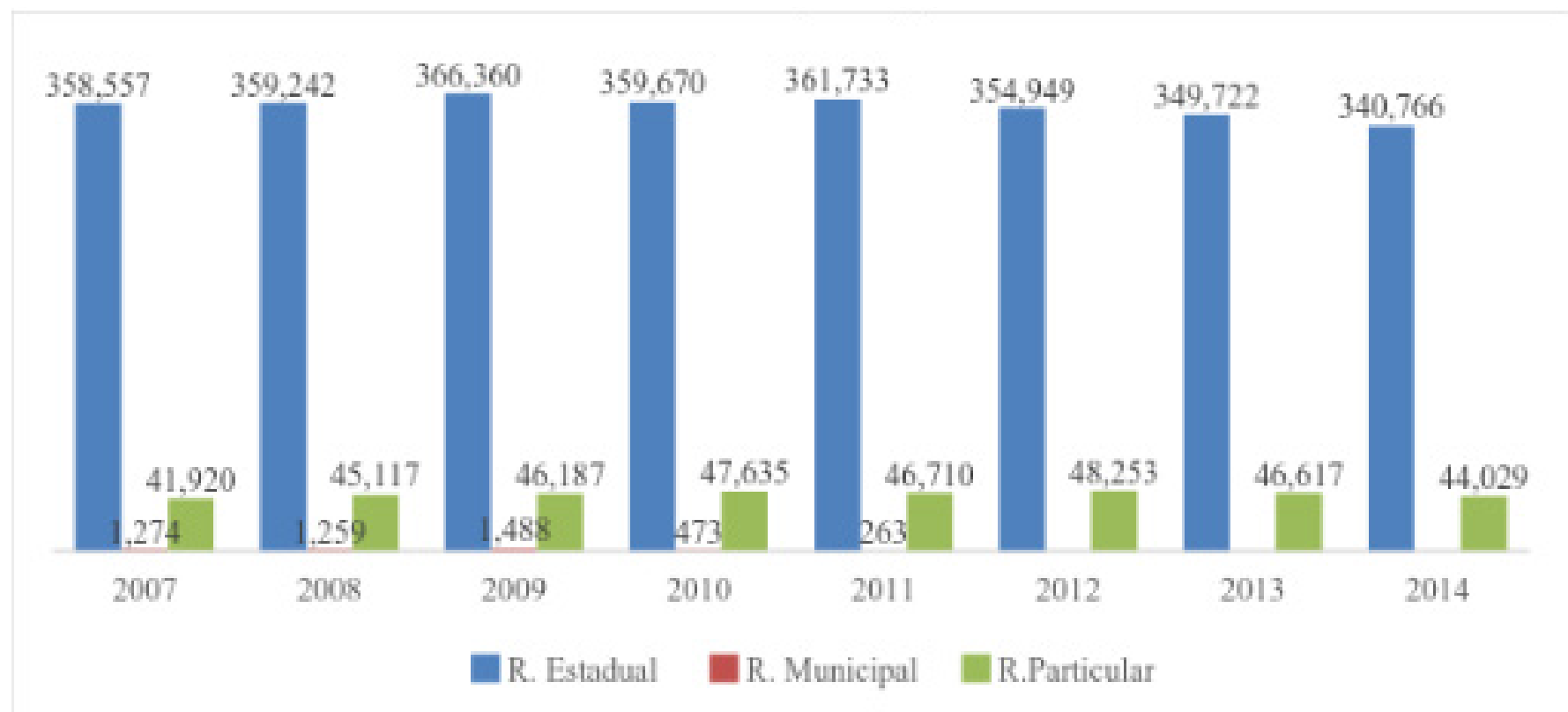

Fonte: Inep/Sinopses Estatísticas da Educação Básica.

\section{Políticas nacionais e POLÍtICAS ESTAdUaIS}

No âmbito nacional, em 2007, o governo federal, por meio da Secretaria de Educação Profissional e Tecnológica (Setec), cria o programa Brasil Profissionalizado, como aporte financeiro adicional aos recursos do Fundeb que "possibilita a modernização e a expansão das redes públicas de ensino médio integradas à educação profissional”. É nesse espaço de novos aportes financeiros que o Ceará vai criar sua rede de escolas estaduais de educação profissional e ampliar o processo de diversificação da oferta nesta etapa de ensino.

A partir de 2008, a Secretaria de Educação assume a política de educação profissional $^{2}$ e dá vazão às demandas locais ajustadas aos objetivos do

1 Ver: $\quad$ shttp://portal.mec.gov.br/index.php?option=com content\&view $=$ article\&id $=12325 \&$ Itemid $=663$. .

2 A oferta de educação profissional era responsabilidade da Secretaria de Ciência e Tecnologia (Secitece), que nos anos 1990 criou uma extensa rede de Centros Vocacionais Tecnológicos (CVT) e Centros Tecnológicos (Centec), que ofertavam cursos técnicos de curta duração e cursos técnicos de nível médio, visando qualificar a população em geral, incluindo egressos do ensino médio. Essa iniciativa funcionou de forma bastante satisfatória, tendo servido, inclusive, de modelo para outras unidades da Federação, como Minas Gerais e Maranhão. 
programa nacional. No período 2008-2014, por meio de financiamento federal, são construídas, reformadas ou ampliadas 106 escolas em 82 munícipios. Estas passam a funcionar em regime de tempo integral, oferecendo ensino médio integrado à educação profissional, chegando a um catálogo de oferta de 53 cursos e 40.897 matrículas.

A adesão da Secretaria de Educação (Seduc) à política nacional de educação profissional cria condições propícias para que, a partir de 2007, passem a coexistir no estado dois tipos de oferta de ensino médio público: o ensino médio regular, que se mantém funcionando a partir de normativos de gestão já definidos anteriormente, e o ensino médio integrado à educação profissional, oferecido em regime de tempo integral, com sistemáticas de gestão administrativa, financeira e pedagógica próprias. A oferta de ensino médio integrado à educação profissional foi a opção de educação profissional adotada pela Seduc para o estado do Ceará. Embora a legislação faculte a oferta de educação profissional nas modalidades concomitante e subsequente ${ }^{3}$, a rede estadual adota, exclusivamente, a modalidade integrada ao ensino médio. Em 2014 as matrículas das escolas profissionais representam $12,0 \%$ da oferta da rede estadual pública. A maior concentração de matrículas públicas, portanto, encontra-se nas escolas de ensino médio regular, que atendem $88,0 \%$ dos alunos.

A análise das propostas de políticas educacionais e de sua implementação nas escolas visitadas permitiu confirmar que, como têm indicado estudos sobre a matéria (BALL; MAGUIRE; BRAUN, 2012), estas se configuram como instâncias de reinvenção das políticas. No caso do Ceará, esse processo de releitura é permeado por três elementos centrais da política educacional do estado, quais sejam: a autonomia da escola, a cooperação (cujo fundamento legal está no regime de colaboração estabelecido pela Constituição de 1988 (Art. 211 e Lei de Diretrizes e Bases da Educação Nacional [LDB], Art. $8^{\circ}$ ) e a participação (fundamentada no princípio constitucional da "gestão democrática do ensino público", Art. 206, VI e LDB, Art. $3^{\circ}$, VIII), pilares que orientam, desde os anos 1990, a política estadual como um todo e a da sua rede de escolas de ensino médio.

A permanência de tais características, independentemente das alterações

\footnotetext{
A lei $n^{\circ} 11.741$, de 16 de julho de 2008 , altera o artigo 36 da LDB e propõe que a educação profissional técnica de nível médio poderá ser desenvolvida na forma subsequente, em cursos destinados a quem já tenha concluído o ensino médio (art. 36-B II) e concomitante, oferecida a quem ingresse no ensino médio ou já o esteja cursando, efetuando-se matrículas distintas para cada curso (art. 36-C, II).
} 
decorrentes das mudanças de partidos políticos no poder, permitiu que, ao longo dos últimos 20 anos, o Ceará construísse um modelo próprio de gestão educacional e escolar, em que convivem orientações de origens distintas, caracterizando-se como um estado onde têm predominado "efeitos de hibridação” (BARROSO, 2005; MAROY, 2011), em que orientações diversas contribuem para a configuração de novos desenhos de política pública. 0 Ceará, um estado carente de recursos naturais, tem se constituído em um laboratório de novas práticas institucionais marcadas por forte mobilização dos atores em busca de superação dos desafios de um território árido e pobre.

Considerando que, assim como a União, os Estados são responsáveis pela “elaboração e execução políticas e planos educacionais, em consonância com as diretrizes e planos nacionais de educação" (LDB, Art. 10, III) os governos estaduais também têm políticas próprias e autônomas em relação ao governo federal. Vale registrar que essa autonomia, entretanto, articula-se fortemente à capacidade de investimento e custeio das unidades federadas, portanto, quanto maior a autonomia financeira, menor a subordinação às políticas federais e vice-versa.

No caso da política educacional, cujos recursos financeiros são assegurados em leis e vinculações constitucionais, estados e municípios contam com esses recursos independentemente da lealdade política, da adesão às políticas federais ou a seu esforço tributário. Isso tende a produzir baixo compromisso com o governo federal, que procura compensar com programas e projetos que representam novos aportes financeiros de curto prazo (ARRETCHE, 2006). 0 Ceará tem adotado a estratégia de "adesão" a esses projetos federais, como é no caso do Brasil Profissionalizado, para a construção da rede de escolas profissionais e, mais recentemente, no uso do Exame Nacional do Ensino Médio (Enem) como estratégia de mobilização para o acesso à educação superior.

\section{EIXOS NORTEADORES DA PESQUISA}

A pesquisa permitiu identificar cinco eixos temáticos comuns às políticas desenvolvidas nos estados integrantes da amostra, conforme se vê na Figura 1. 


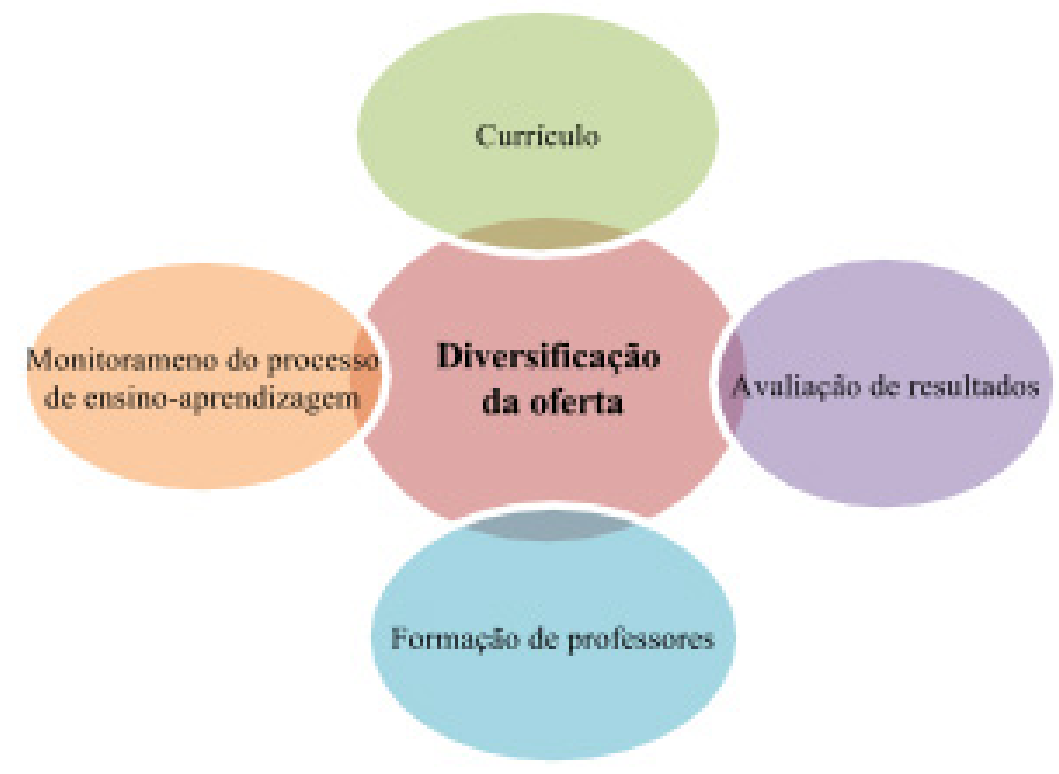

Fonte: Elaborado pelas autoras.

No caso da política educacional cearense, dois eixos temáticos se destacam, configurando-se como componentes centrais da política de ensino médio: a diversificação da oferta e a avaliação de resultados. 0 currículo e a formação de professores, por sua vez, parecem representar componentes secundários na formulação e implementação de políticas no estado. Por outro lado, o monitoramento do processo de ensino-aprendizagem é viabilizado pela atuação dos organismos regionais ligados à Secretaria de Educação, instâncias administrativas com papel e funções estratégicas no desenho das políticas educacionais cearenses. A seguir, procurar-se-á apresentar uma descrição da pesquisa realizada, a partir dos cinco eixos temáticos, na expectativa de responder à questão norteadora da investigação. Em seguida, destacar-se-ão os aspectos mais relevantes de cada um dos eixos temáticos identificados na pesquisa.

\subsection{Diversificação da oferta}

Como já foi destacado, o ensino médio público no Ceará está distribuído em dois tipos de oferta: o ensino médio profissional de tempo integral e o ensino médio regular de turno único. 0 trabalho de campo permitiu constatar uma peculiaridade praticamente invisível do ensino médio regular: a oferta de matrículas em espaços localizados em distritos ou comunidades rurais, 
conhecidos como "extensões rurais" ou "anexos"4. Embora vinculados formalmente a uma escola-sede, seu locus escolar encontra-se, muitas vezes, a quilômetros de distância. Segundo dados obtidos junto à Seduc, em 2015, há 34.787 alunos matriculados nas extensões rurais, quantidade semelhante à de estudantes em escolas de ensino médio profissional de tempo integral. Isso significa que uma verdadeira rede se oculta em meio às matrículas de ensino médio regular, havendo assim não apenas dois, mas três tipos de oferta, com condições de funcionamento profundamente diferenciadas entre umas e outras.

Em depoimento aos pesquisadores do projeto, o então secretário de Educação ${ }^{5}$ reconheceu que a existência de uma oferta diversificada tem gerado problemas de equidade na rede pública, como é perceptível no trecho a seguir:

\begin{abstract}
[...] eu acho que existe uma demanda e sempre existirá no noturno e que deverá ser atendida adequadamente no noturno e aí eu digo assim, adequadamente não é o que se faz hoje, que é uma réplica malfeita do que se faz no diurno. Acho que essa diversidade tende a se tornar um problema de equidade e acho que sendo bem pragmático, um problema de cada vez. O problema que a gente tentou resolver com a escola profissional de tempo integral é um problema de necessidade e aspirações da juventude e de suas famílias, necessidades econômicas e por outro lado, uma tentativa de afirmar que é possivel construir um modelo de escola pública respeitada, que seja referência na sua comunidade, para contrapor um pouco esse discurso de que escola pública não funciona e acho muito importante operar nesse nível simbólico, tanto para o estado, mas, sobretudo para aquelas comunidades onde as escolas estão (Ceará, secretário estadual de educação).
\end{abstract}

Se é verdade que o estado tem empreendido esforços no sentido de responder ao desafio do ensino médio, é inegável que a diferenciação da oferta no interior da própria rede resulta em problemas de iniquidade. A comparação entre o ensino médio profissional de tempo integral e o ensino médio regular de turno único ofertado nos anexos expõe um problema que cedo ou tarde precisará ser enfrentado de modo a responder ao desafio do direito social à educação (Constituição Federal, Art. 6을 e Art. 205), em atendimento ao princípio da "igualdade de condições para o acesso e permanência na escola" (CF, Art. 206, I) e ao dever do Estado para com a "educação básica obrigatória e gratuita dos 4 (quatro) aos 17 (dezessete) anos de idade” (CF, Art. 208, I).

\footnotetext{
Os anexos ou extensões rurais existem na oferta de ensino médio no Ceará desde o começo dos anos 2000. Via de regra, funcionam em escolas municipais cedidas pela prefeitura para, no turno noturno, atender a clientela de ensino médio. A matrícula de ensino médio é variável, existindo situações em que mais de 150 alunos frequentam esses espaços. São vinculados à escola estadual que fica localizada na sede, que além de assumir a matrícula no Censo Escolar, dá todo o suporte pedagógico e de gestão.

Maurício Maia Holanda foi substituído por Idilvan Alencar em maio de 2016.
} 


\subsection{Avaliação de resultados}

Os mecanismos de avaliação de desempenho dos alunos vêm se constituindo como vertente importante da formulação e implementação da política educacional da rede estadual. Tal processo teve início com a criação do Sistema Permanente de Avaliação da Educação Básica (Spaece) ${ }^{6}$, em 1992. Gradativamente aprimorado e ampliado, a partir de 2003 o Spaece passa a ser incorporado como mecanismo de gestão pública. Em 2007 há um aprofundamento e consolidação de tal política, com ampliação do foco e dos desdobramentos da avaliação de larga escala.

A adesão maciça ao Enem a partir de 2010, por sua vez, provocou mudanças na gestão das escolas públicas cearenses de ensino médio, levando-as a ajustarse a metas associadas a resultados nesses exames. Tal movimento contribuiu para uma homogeneização do currículo, que mesmo sem orientação ou marcos normativos estaduais, está se alinhando, gradativamente, em torno das matrizes de referência desses exames.

Embora se perceba a existência de foco em resultados de desempenho dos alunos, em ambos os tipos de escolas de ensino médio observa-se que a cobrança junto ao corpo docente e a pressão junto aos alunos é maior naquelas de educação profissional. Os mecanismos de gestão apresentam fortes características de accountability e gerencialismo, sendo a política de premiação/bônus criada pelo governo do estado um mecanismo de indução muito valorizado pela gestão escolar. Entre professores e estudantes, as referências às avaliações externas e ao foco nos resultados são menos evidentes e mais associadas às questões de acesso dos estudantes de ensino médio à educação superior.

A presença de uma cultura de provas, de simulados e de atividades preparatórias visando à aplicação das avaliações externas foi constatada em todas as escolas, com maior ênfase nas de educação profissional, onde todos os diretores parecem acompanhar os resultados de seus alunos. A concessão de prêmios para alunos com bom desempenho no Enem, referida e valorizada pelos entrevistados, ao que tudo indica, tem se constituído em fator de frustração, por dificuldades operacionais no que diz respeito à aquisição e distribuição dos prêmios, que, via de regra, são computadores.

O Spaece é realizado anualmente e consiste em aplicação de provas, segundo uma matriz de referência previamente definida no ensino fundamental - Spaece-Alfa: $2^{\underline{a}}$ série; $5^{\circ}$ e $9^{\circ}$ anos e no ensino médio (1aㅡ $2^{\underline{a}}$ e $3^{\underline{a}}$ séries). Em todas as séries, a avaliação é censitária e inclui as redes municipais de ensino. 
Para além de uma gestão orientada por metas e resultados, a cultura de avaliação surte outros efeitos sobre as escolas. A autonomia escolar, reconhecida pela própria Seduc como um princípio orientador da política educacional cearense, é vivenciada de forma relativa quando se questiona os diretores sobre tal assunto. O sistema de monitoramento de resultados realizado pela Seduc não consegue captar o conjunto de variáveis mobilizadas pela escola para atender as demandas do órgão central, pois é realizado com base em informações disponibilizadas pelas avaliações, o que coloca limitações expressas nas palavras de um diretor que diz que o trabalho da escola "nem sempre pode ser detectado através de um índice”. Conforme antes mencionado, em todas as etapas da pesquisa constatou-se a forte presença de uma cultura de avaliação. Se este é um componente estratégico da política desenvolvida pelo estado, as formas de implementação diferem de acordo com as escolas. 0 trabalho de campo permitiu observar significativas diferenças nos modos de lidar com esse elemento estratégico da política, assim como sua incorporação ao cotidiano dos processos de ensino-aprendizagem.

A complexidade da organização e o nível de detalhamento da gestão por resultados no âmbito das escolas parece variar em função do perfil dos gestores, desde um minucioso acompanhamento turma a turma, aluno a aluno, a uma abordagem centrada em aulas extras ministradas por professores voluntários.

\subsection{Currículo, matrizes e exames}

Se as secretarias de Educação da maioria das unidades da federação têm se empenhado na construção de orientações curriculares para seus sistemas de ensino, tal preocupação não parece evidente no Ceará, o que não significa a ausência de interesse pela matéria.

O trabalho de campo permitiu fazer algumas observações acerca deste eixo temático. A primeira, e mais instigante, por certo, diz respeito à existência, ou não, de um currículo oficial. Há diferenças significativas na fala dos gestores e na percepção dos diretores. Enquanto os primeiros informam não haver um currículo oficial, exceto um documento produzido em 2008, as escolas afirmam de forma categórica a existência de um currículo oficial e se reportam ao mesmo documento como referência a ser seguida.

Na visão dos diretores escolares, no entanto, a questão do currículo está intimamente articulada com as matrizes de exames como o Spaece e o Enem, como se verifica no depoimento de um diretor: 
[...] em termos de Seduc, tem um material, uma proposta de currículo, já com base nos descritores do Enem e do Spaece. Aí a gente tem flexibilizado muito o currículo em função disso, a gente até já vê que o professor já está seguindo muito mais, deixando de seguir um livro e está seguindo um currículo que seja construído mesmo (Ceará, diretor de escola de município de grande porte).

Entre os professores e os estudantes notou-se certo conformismo em relação à presença de um currículo excessivamente sobrecarregado e com enfoque notadamente disciplinar. Ainda que reconheçam tal sobrecarga, parecem lidar com o problema como se não estivesse na esfera da autonomia escolar a decisão de promover mudanças. Os estudantes das escolas de educação profissional, de modo especial, reclamam da sobrecarga de disciplinas e do excessivo número de horas despendido em sala de aula sem, no entanto, questionarem o sentido de tais atividades em seus itinerários formativos.

O então Secretário de Educação, por sua vez, expressou uma visão um tanto pragmática do currículo, ao afirmar que este não é objeto prioritário da administração central, uma vez que, na sua percepção, “[...] o currículo se efetiva principalmente em função do que se mede para entrar na universidade e em função da cultura pedagógica que se construiu no país" (Ceará, secretário de educação do estado).

Para além de representar aspecto secundário da política educacional do estado, merecem registro algumas escolhas feitas pelos órgãos centrais e pelas escolas. No que se refere às escolas de ensino médio profissional, por exemplo, a opção parece ter incidido em uma versão tradicional do currículo, com uma carga de conteúdos disciplinares que parece excessiva para professores e alunos, segundo revelam as observações das escolas e as entrevistas. As ofertas e opções formativas nem sempre parecem estar em sintonia com as demandas locais e interesses individuais de estudantes que, de alguma maneira, disputam a matrícula nos cursos de maior prestígio entre os jovens, como aqueles ligados à informática ou às profissões da saúde.

As escolas de ensino médio regular, por sua vez, também parecem empenhadas numa oferta caracterizada pelo excesso de conteúdos disciplinares, com raras janelas orientadas para projetos pedagógicos de caráter interdisciplinar. Durante o trabalho de campo, por exemplo, não foram observadas iniciativas de tal natureza, seja por parte da direção, da coordenação, de professores ou de estudantes. É possível que a ausência de tais preocupações seja um reflexo do caráter secundário de uma política de desenvolvimento curricular no âmbito da Secretaria de Educação do Ceará, mas seria necessário aprofundar 
estudos sobre o tema antes de formular qualquer suposição mais efetiva em tal direção.

\subsection{Monitoramento do processo de ensino-aprendizagem}

O trabalho da Secretaria junto às escolas de sua rede consiste em um acompanhamento, desenvolvido por meio de seus órgãos intermediários. Embora a Seduc possua um Sistema de Informações Gerenciais (Sige), os esforços relativos ao andamento dos processos de ensino-aprendizagem se concentram no acompanhamento pedagógico.

No âmbito interno da Secretaria de Educação, o acompanhamento às escolas é feito por equipes técnicas que desempenham tarefas específicas. Na visão da equipe técnica da Seduc, o sistema de acompanhamento por parte dos órgãos intermediários à rede de escolas se diferencia, tendo as escolas profissionais um monitoramento mais sistemático, com um programa de formação associado.

$\mathrm{Na}$ esfera da gestão escolar, todos os estabelecimentos estaduais contam com um núcleo gestor, cuja composição varia conforme o tamanho das unidades e é integrado por pelo menos três componentes que exercem funções gratificadas: um diretor, uma coordenação pedagógica e uma secretaria escolar. $\mathrm{O}$ acompanhamento aos docentes das diferentes áreas de conhecimento é feito por um professor da escola (efetivo ou temporário) - o Professor Coordenador de Área (PCA) -, com regime de 40 horas semanais, 20 das quais dedicadas a esta atividade. Para tanto, a experiência e liderança perante seus pares são requisitos importantes, uma vez que ele atua junto ao coordenador pedagógico no acompanhamento da avaliação do ensino, do processo de aprendizagem, bem como dos resultados do desempenho dos alunos. Por não dispor de uma estrutura própria de carreira com incentivos ao exercício de cargos técnicos, a Secretaria acaba por preencher as lacunas relativas à escassez de recursos humanos com docentes que, para tanto, recebem incentivos financeiros de modo a compensar perdas salariais decorrentes de seu afastamento da sala de aula.

\subsection{Formação de professores}

Embora os eixos temáticos tenham definido o termo "formação de professores" para caracterizar as ações desenvolvidas com foco na docência, a expressão "políticas docentes" talvez seja mais apropriada para referir tais iniciativas, pelo menos no caso do Ceará, uma vez que envolvem não apenas ações de formação no sentido estrito, como também políticas de recrutamento de 
pessoal docente, regime de trabalho e outros temas correlatos, alguns dos quais aprofundados na pesquisa. A pesquisa evidenciou algumas tendências, a saber: rotatividade docente relativamente baixa nas escolas da amostra, inadequação da formação docente em das escolas pesquisadas e alto nível de esforço docente, sobretudo nas escolas de ensino médio regular de um turno.

O exame de dados relativos ao número de professores temporários ou regidos pela Consolidação das Leis do Trabalho (CLT) encontrados nas escolas estaduais revela alguns números impactantes. Mesmo depois de três concursos realizados em tempos recentes, a grande maioria dos docentes das escolas visitadas é constituída por professores temporários.

A presença dos professores em tempo integral nas escolas profissionais se mostrou relevante, especialmente por possibilitar maior integração entre eles, permitir ajustes nos planejamentos pedagógicos de forma rápida e articulada, e oferecer apoio aos alunos a qualquer momento que eles demandem. Se por um lado parecem aspectos positivos do ponto de vista de melhoria da qualidade do atendimento aos alunos, por outro lado os próprios docentes reconhecem que trabalham além da sua carga horária estabelecida.

Quanto às políticas de formação continuada, as entrevistas não apresentaram evidências de que a Secretaria tenha concentrado esforços em ações direcionadas a professores do ensino médio. De maneira geral, o que se encontrou foram formações tópicas desenvolvidas no âmbito das próprias escolas.

Na perspectiva dos diretores, as formações docentes acontecem na própria escola e incluem momentos pedagógicos diversos, especialmente ampliados depois da Lei do Piso, que assegurou $30 \%$ da carga horária para atividades que podem ser de formação, como podemos constatar no depoimento seguinte:

[...] com a adesão da questão das 27 horas para o professor, nós organizamos as nossas semanas aqui na escola com relação à formação, então nós temos hoje propriamente dito a formação, ela é do coordenador da escola (Ceará, diretor de escola de município de médio porte).

Já na escola de ensino médio de Fortaleza, o diretor observa que quanto à formação de professores,

Realmente a gente está carente disso daí, houve esse último projeto do governo agora, o Pacto que ele infelizmente foi [...] deu uma reviravolta na formação dos professores até porque o grupo que foi formado aqui dos professores orientadores eles fizeram um trabalho assim muito bom. Deu uma mexida o professor passou a levar com mais seriedade o curso (Ceará, diretor de escola de município de grande porte). 
Quanto às iniciativas da escola no planejamento de ações de formação para os docentes, um diretor assume que "a gente entende que formação são essas reuniões que a gente faz de planejamento, não deixa de ser uma formação porque a gente pega a realidade da escola e vamos discutir em cima dela e traçar a meta" (Ceará, diretor de escola de município de grande porte). Do mesmo modo, os professores trazem questões da sala de aula para discutir com os colegas, fato considerado relevante, inclusive a gestão escolar estimula tal iniciativa, pois considera uma forma de empoderar os docentes.

Como evidenciaram os depoimentos citados, assim como entrevistas junto à equipe técnica do ensino médio da Seduc e a docentes das escolas da amostra, as ações de formação, em anos recentes, têm se restringido às atividades e momentos de planejamento, quando o corpo docente desenvolve estudos e compartilha experiências de modo a preencher lacunas no que diz respeito a conteúdos que subsidiem suas atividades de ensino. Sem desmerecer a relevância da troca de conhecimento entre os docentes, é forçoso reconhecer que tal modalidade de formação tem suas limitações, passando ao largo das necessidades docentes de desenvolvimento profissional e de aprofundamento nas áreas específicas do saber curricular.

Sem sombra de dúvida, esta é uma lacuna visível nas políticas estaduais. No longo prazo, pode contribuir para o esgotamento de um modelo fortemente sustentado no fortalecimento da gestão escolar e que, de certo modo, secundariza a formação docente como componente essencial do currículo.

\section{EIXOS TRANSVERSAIS DA PESQUISA}

0 trabalho de campo possibilitou perceber que, para além das diretrizes comuns de cada política governamental proposta, as escolas possuem um repertório de estratégias que permitem a transposição dessas diretrizes para as realidades locais, marcadas por contextos e variáveis próprias. Os três eixos transversais - juventude, território e identidade da escola - permitem visualizar essas estratégias.

\subsection{Juventude, cultura e escola}

Compreender a relação da cultura com a juventude que frequenta o ensino médio em escolas públicas, seja ela da periferia de uma metrópole ou localizada em cidades de pequeno e médio porte no interior do estado do Ceará, nos remete a uma afirmação de Dayrell (2007) de que “o jovem que chega às escolas públicas, na sua diversidade, apresenta características, 
práticas sociais e um universo simbólico próprio que o diferencia e muito das gerações anteriores" (DAYRELL, 2007, p. 1107). A pesquisa de campo realizada nas seis escolas revelou que, de fato, vive-se um período em que é impossível falar de um conceito único de juventude, mas de juventudes. Essa visão é compartilhada pelo então secretário, quando afirma que "política de ensino médio para mim é política de juventude".

Dayrell (2007) também discute o cotidiano dos jovens brasileiros e o "princípio da incerteza":

[...] eles se deparam com verdadeiras encruzilhadas de vida, nas quais as transições tendem a ser ziguezagueantes, sem rumo fixo ou predeterminado. Se essa é uma realidade comum à juventude, no caso dos jovens pobres os desafios são ainda maiores, uma vez que contam com menos recursos e margens de escolhas, imersos que estão em constrangimentos estruturais (DAYRELL, 2007, p. 1113-1114).

A diversificação da oferta de ensino médio da rede pública estadual cearense, especialmente depois da criação da rede de escolas profissionais, se constitui como um campo de oportunidades para que os jovens possam realizar escolhas, embora limitadas e contingenciadas por exigências que, muitas vezes, os constrangem. Tal é o caso do processo seletivo para as escolas de ensino médio integrado à educação profissional, que permite que aqueles que a frequentam possam ser mais bem preparados para o Enem e outros processos seletivos que propiciam o acesso ao ensino superior.

Os estudantes de escolas profissionais expressam um desejo de mobilidade social grande, e poucos têm a intenção de atuar como técnicos de nível médio, vendo nesta formação uma possibilidade de renda para pagar os estudos de nível superior. Na visão da gestão, as escolas de ensino médio integrado à educação profissional redimensionaram sua missão inicial quando a Seduc passou a estimular a adesão ao Enem. Hoje, essas escolas cumprem os dois papéis - formar profissionais de nível médio e preparar para os processos seletivos de acesso ao ensino superior. Jovens estudantes dessas unidades revelam um senso pragmático na intenção de exercer a profissão para a qual estão se preparando como estratégia para ascender e, eventualmente, financiar seus estudos no ensino superior.

$\mathrm{Na}$ entrevista com os alunos perceberam-se níveis de maturidade intelectual e socioemocional diferentes entre os que frequentam as escolas profissionais e as escolas de ensino médio regular. Na visão dos alunos, nas escolas profissionais eles são levados a conceber seu projeto de vida e, com isso, aprendem a dimensionar o “sonho" e planejar os passos necessários 
para atingi-lo. No entanto, há que se questionar em que medida essa homogeneização de posturas é, de fato, espontâneo, ou forjado pela escola, pois, segundo Abramovay (2015),

Na escola, o jovem é despido da condição social de ser jovem e se transforma em "aluno", ou seja, é visto por uma perspectiva exterior a ele, em uma imposição normativa do sistema de ensino, perdendo-se de vista a diversidade, as buscas e os parâmetros de comportamento que fazem parte das modelagens de juventudes. A escola desconsidera, portanto, a cultura juvenil, a qual se caracteriza por ser dinâmica, diversa, flexível e móvel (ABRAMOVAY, 2015, p. 31).

\subsection{Território e territórios}

As questões relativas à distribuição territorial enquanto fator de aprofundamento das desigualdades socioespaciais revelaram aspectos interessantes, especialmente diante do cotejamento com as ofertas do ensino médio nas escolas de ensino médio regular, nas escolas de educação profissional e nas extensões rurais. Um aspecto a registrar que se refere à questão territorial diz respeito às diferenças entre as escolas dos municípios do interior e da capital. Nos primeiros, é perceptível a maior permanência dos gestores e professores nas escolas, enquanto na capital, especialmente os docentes, inclusive das escolas de educação profissional, permanecem menos tempo nas escolas, muitos com compromissos em outras escolas ou atividades. De maneira geral, observa-se que as desigualdades socioespaciais parecem menos visíveis nas percepções dos jovens estudantes das escolas do interior; a consciência da pobreza e das limitações dos sonhos é mais aguda entre os jovens da capital, habitantes de territórios da periferia, muitas vezes com alta vulnerabilidade social.

Um aspecto que chamou a atenção dos pesquisadores refere-se a uma certa "sacralização" do espaço da escola na região onde está localizada. Nos bairros da capital, conhecidos pela vulnerabilidade social e violência, a rua na qual se localiza a escola parece preservar um clima de normalidade e, no depoimento de alguns diretores, a escola é protegida de agressões, invasões e outros tipos de violência por meio de pactos implícitos ou explícitos com grupos sociais responsáveis por esse tipo de violência.

Nesse processo de construção de parceria com a comunidade, um diretor afirma que não só o contato direto com pais e familiares, mas também o trabalho desenvolvido em torno da ideia de que a escola é da comunidade, sem, no entanto, perder os valores basilares que constituem a razão de ser da escola, que 
[...] primeiro a escola passou a oferecer a educação, o conhecimento. A mãe "eu sei que o meu filho está lá na escola, mas ele está aprendendo". E aí junto com a questão de oferecer educação acho que ao longo do tempo os pais foram observando isso, então também a questão da segurança que também foi, houve tempos em que não era tão fácil, mas aí foi uma construção que perdura até hoje (Ceará, diretor de escola de município de grande porte, grifos nossos).

A presença dos anexos ou extensões rurais chamou a atenção dos pesquisadores desde a primeira visita a campo. Uma situação peculiar, observada em apenas uma das escolas, fez com que o interesse sobre 0 tema fosse ampliado em virtude de pouco se falar e menos ainda saber como funciona essa oferta, poder-se-ia dizer invisível, à luz das coletas oficiais de dados, como o Censo Escolar. 0 que se percebeu foi a construção de identidade com um território, completamente diferente do que a literatura sobre território e juventude aborda. Quando indagados sobre o pertencimento à escola-sede, os alunos são categóricos em afirmar que se sentem como se fossem de "De lá, é como se fosse uma família gigante” (Ceará, aluno de escola anexo à extensão rural de município de médio porte).

Os professores que atuam nos anexos, muitos moradores na própria comunidade, representam baluartes na preservação das extensões rurais nesses territórios. Embora reconheçam problemas de qualidade na oferta dessas turmas, defendem a permanência dos anexos com argumentos que se ancoram em suas próprias histórias de vida. Na visão dos docentes de tais unidades, os anexos representam um território a ser preservado, pois significam a garantia de um direito - no caso, o ensino médio. Sem ignorar tal dimensão do problema, merece registro a visível precariedade de recursos humanos e infraestrutura das extensões rurais, o que contribui para o aprofundamento das diferenças entre os tipos de escolas identificados na amostra e se constitui em desafio para a superação das iniquidades que se colocam para alunos de uma mesma rede escolar.

\subsection{Identidade da escola}

Sendo a autonomia da escola um componente basilar da política educacional cearense, a identidade da escola é dimensão central para o entendimento da dinâmica estabelecida entre o órgão central e a ponta do sistema. Para melhor compreensão desse eixo transversal, é oportuno retomar a perspectiva teórica de Torres (2005), que situa a escola como portadora de valores decorrentes de sua construção histórica. Seria possível afirmar, assim, que cada escola representa um "pequeno mundo", o qual resulta de uma síntese da cultura que foi sendo construída institucionalmente. Nesse sentido, pode-se dizer 
que as escolas imprimem suas próprias marcas à forma como desenvolvem as políticas formuladas pela Secretaria. Do mesmo modo, criam iniciativas próprias na medida de suas necessidades e interesses. Isso vale tanto para as políticas centrais ao projeto educativo do estado, como para elementos relativos a aspectos associados ao sucesso escolar, como por exemplo, o clima escolar. Tal traço revelou-se presente nas seis escolas visitadas no Ceará, referendando as expectativas associadas a seus bons resultados em contextos socioespaciais adversos.

É perceptível o alinhamento entre as concepções da equipe técnica da Seduc e as equipes dos órgãos intermediários. As orientações advindas da Seduc e regionais são recebidas pelas escolas, mas percebem-se diferenciações no processo de implementação em cada estabelecimento de ensino. Essas diferenciações estão mais relacionadas ao modus faciendi, uma vez que o foco permanece comum. Confirma-se a hipótese de que se as políticas, programas e projetos (federais e estaduais) são os mesmos, as formas de interpretação diferem: são seis escolas, seis diretores, seis visões de mundo e seis projetos em construção.

Vários outros aspectos do que se observou do cotidiano das escolas durante o trabalho de campo permitem constatar as diferenças na identidade das escolas. Esse jeito próprio de lidar com os problemas pode ser percebido desde os modos de acompanhamento dos processos de ensino-aprendizagem desenvolvidos pelo núcleo gestor de cada escola à forma como a liderança é exercida por parte dos gestores. Observam-se lideranças mais ou menos carismáticas - e todos os diretores entrevistados, sem distinção, parecem possuir visível liderança perante a comunidade de sua escola e por ela são respeitados. Vários depoimentos de professores e estudantes registram reconhecimento das qualidades do gestor à frente da escola à qual pertencem.

\section{5. À GUISA DE CONCLUSÃO}

Em sintonia com a concepção teórica adotada (BALL; MAGUIRE; BRAUN, 2012; TORRES, 2005), observou-se que a implementação de políticas, programas e projetos nas escolas pesquisadas mostrou-se estreitamente associada a uma cultura organizacional própria de cada uma das unidades pesquisadas. Nesta perspectiva, é oportuno lembrar que as iniciativas governamentais são “fatores exógenos” às escolas (porque são originários do Ministério da Educação ou da Secretaria de Educação do Ceará), ao passo que seus próprios recursos (humanos - professores, equipe gestora, alunos e funcionários -, materiais e imateriais) são "fatores endógenos". Como cada escola é fruto 
de uma história construída a partir dos caminhos que a levaram a configurar sua identidade atual, não são as mesmas as formas como interpretam e reinterpretam as políticas.

Sem sombra de dúvida, a face mais visível da presença federal é o Enem, apropriado pela Secretaria de Educação e sua rede de escolas como uma política com cores próprias. Notou-se que este exame mobiliza toda a comunidade escolar visando à participação do maior número possível de alunos das escolas estaduais no certame.

As escolas da amostra parecem conviver de forma natural com uma cultura de avaliação externa por parte da Seduc, introduzindo mecanismos de preparação tanto para as provas do Spaece quanto para o Enem. Em todas as unidades pesquisadas observou-se a presença de estratégias de preparação para as avaliações externas, cujo alvo mais direto e o principal chamariz para os alunos é o acesso ao ensino superior.

Observou-se nas escolas pesquisadas que a maioria dos diretores tem uma avaliação positiva acerca da política de bônus adotada pela Seduc, com apenas uma voz discordante na afirmação de que "em certo ponto, ela ajuda a menosprezar algumas unidades" (Ceará, diretor de escola de município de grande porte, grifos das autoras). Em todas as unidades da amostra encontrou-se um clima organizacional positivo expresso em diferentes dimensões. Do ponto de vista de infraestrutura, todas as escolas pareceram bem conservadas, mantidas e limpas. Nenhuma das unidades pesquisadas apresentava pichações ou qualquer tipo de depredação. Mensagens positivas, alusões (inclusive fotografias) a alunos aprovados no vestibular e troféus conquistados em certames ocupam lugar de destaque nas paredes ou estantes das escolas.

Do ponto de vista humano, o clima pareceu cordial, respeitoso e amistoso. Há um visível alinhamento entre os diferentes segmentos da escola no que se refere aos objetivos de aprendizagem e o clima organizacional é bastante positivo; reconhece-se que a participação de todos é fator importante para a conquista de bons resultados.

Um desafio à melhoria do ensino médio cearense é o enfrentamento da iniquidade gerada no interior das escolas da rede estadual. A depender do seu território de origem, os jovens alunos do ensino médio podem ter oportunidades diametralmente distintas de escolarização. O princípio da “igualdade de condições para o acesso e permanência na escola” (CF, Art. 206, I) deve, pois, estar no centro das formulações de novas políticas. 


\section{Secondary education in the state of Ceará: equality versus quality in the implementation of the right to education}

Abstract: This article analyzes the process of implementation of educational policies to promote quality and equity in youth education, and how schools assimilated and incorporated these policies. It summarizes results of a study with a sample of six secondary schools in three cities (Fortaleza, Canindé and Paraipaba) in the State of Ceará, using quantitative and qualitative methods which include the analysis of indicators, literature review, document analysis and field research. Results showed a strong presence of large-scale assessment, as well as diversity in education offer. We found that $88 \%$ of students attend regular part-time schools, while $12 \%$ attend vocational fulltime schools. Teaching-learning conditions vary between these two types of education offer and this differentiation is more dramatic in the so-called "rural extensions" or annexes, which are attended by $11 \%$ of the students. This situation has contributed to a secondary education offer diversification marked by inequality factors. In the schools visited, we found a very positive school environment regarding teachers, students and the management, the last being strongly engaged in the pursuit of good results.

Keywords: Ceará. Secondary education. Socio-spatial inequalities. Diversity in education offer. 


\section{Enseñanza media en el estado brasileño de Ceará: la igualdad frente a la calidad en la implementación del derecho a la educación}

Resumen: Este artículo analiza el proceso de implementación de las políticas educacionales y la asimilación e incorporación de dichas políticas por parte de las escuelas con vistas a promover la calidad y la equidad educacional en la formación de los estudiantes. Sintetiza resultados de una investigación desarrollada a partir de un muestreo de seis escuelas de enseñanza media, ubicadas en tres municipios del estado brasileño de Ceará, mediante la realización de estudios de naturaleza cuanticualitativa, incluyendo análisis de indicadores, revisión de literatura, análisis documental e investigación de campo. Dicha investigación reveló una fuerte presencia de la evaluación a gran escala y la diversificación de la oferta escolar. Constató que el 88 \% de los alumnos están en escuelas de enseñanza regular de un turno y el 12 $\%$ en escuelas de formación profesional a tiempo completo. Las condiciones de enseñanza-aprendizaje entre estos dos tipos de oferta se diferencian y agravan en las llamadas "extensiones rurales" o anejos, donde estudian el 11 $\%$ de los estudiantes. Esta situación viene contribuyendo a una diversificación de la oferta marcada por elementos de iniquidad.

Palabras clave: Ceará. Enseñanza media. Desigualdades socioespaciales. Diversificación de la oferta. 


\section{REFERÊNCIAS}

ABRAMOVAY, Miriam (Coord). Juventudes na escola, sentidos e buscas: Por que frequentam? Brasília-DF: Flacso, Brasil, OEI, MEC, 2015. 346 p. Disponível em: $\quad$ http://flacso.org.br/?publication=juventudes-na-escola-sentidos-ebuscas-por-que-frequentam». Acesso em: 17 jan. 2016.

ARRETCHE, Marta. Federalismo e políticas sociais no Brasil: problemas de coordenação e autonomia. In: SARAVIA, Enrique; FERRAREZI, Elisabete (Org.). Políticas públicas. Brasília: Enap, 2006. (Coletânea, v. 2, p. 91-110).

BALL, Stephen J.; MAGUIRE, Meg; BRAUN, Annette. How schools do policy: policy enactments in secondary schools. London: Routledge, 2012.

BARROSO, João. O Estado, a educação e a regulação das políticas públicas. Educação \& Sociedade, Campinas, v. 26, n. 92 - Especial, p. 725-751, out. 2005.

BRASIL. Emenda constitucional no 53, de 19 de dezembro de 2006. Dá nova redação aos arts. 7ํ, 23, 30, 206, 208, 211 e 212 da Constituição Federal e ao art. 60 do Ato das Disposições Constitucionais Transitórias. Disponível em: 〈http://www.planalto.gov.br/ccivil_03/ Constituicao/Emendas/Emc/ emc53. htm>. Acesso em: 13 mar. 2013.

- Presidência da República. Casa Civil. Subchefia para Assuntos Jurídicos. Constituição da República Federativa do Brasil de 1988. Disponível em: 〈http://www.planalto.gov.br/ccivil_03/constituicao/constituicao.htm〉. Acesso em: 16 fev. 2014.

Presidência da República. Casa Civil. Subchefia para Assuntos Jurídicos. Lei no 9.394, de 20 de dezembro de 1996. Estabelece as diretrizes e bases da educação nacional. Disponível em: 〈http://www.planalto.gov.br/ ccivil_03/leis/19394.htm>. Acesso em: 23 mar. 2014.

CASTRO, Vanessa Gomes de; TAVARES JUNIOR, Fernando. Jovens em contextos sociais desfavoráveis e sucesso escolar no ensino médio. Educação \& Realidade, Porto Alegre, v. 41, n. 1, p. 239-258, jan./mar. 2016.

CENPEC. Currículos para os anos finais do ensino fundamental: concepções, modos de implantação e usos. Relatório Final. São Paulo, 2015. Disponível em: 〈http://ftp.cenpec.org.br/com/portalcenpec/biblioteca/Relatorio_Pesquisa_ Curriculos_EF2_Final.pdf $>$. Acesso em: 4 abr. 2016. 
DAYRELL, Juarez. A escola "faz" as juventudes? Reflexões em torno da socialização juvenil. Educação \& Sociedade, Campinas, v. 28, n. 100 Especial, p. 1105-1128, out. 2007.

MAROY, Christian. Em direção a uma regulação pós-burocrática dos sistemas de ensino na Europa? In: OLIVEIRA, Dalila Andrade; DUARTE, Adriana (Org.). Políticas públicas e educação: regulação e conhecimento. Belo Horizonte: Fino Traço, 2011. p. 19-46.

TORRES, L. L. Cultura organizacional no contexto escolar: o regresso à escola como desafio na reconstrução de um modelo teórico. Ensaio: Avaliação e Políticas Públicas em Educação, Rio de Janeiro, v. 13, n. 49, p. 435 - 451, out./ dez. 2005. Disponível em: 〈http://www.scielo.br/pdf/ensaio/ v13n49/29240. pdf $>$. Acesso em: 29 jan. 2015.

YIN, Robert K. Estudo de caso: planejamento e métodos. 3. ed. Porto Alegre: Bookman, 2005.

Sobre as autoras:

Sofia Lerche Vieira é doutora em Filosofia e História pela Pontifícia Universidade de São Paulo (PUC/SP). Atua como professora do Programa de Pós-graduação em Educação da Universidade Estadual do Ceará (Uece).

E-mail: sofialerche@gmail.com

Eloísa Maia Vidal é doutora em Educação pela Universidade Federal do Ceará e professora da Uece.

E-mail: eloisamvidal@yahoo.com.br

Recebido em: março de 2016

Aprovado em: maio de 2016 